\title{
Breve Análise de Periódicos da Área de Ciências DA INFORMAÇão SOBRE AS TEORIAS de IDENTIDADE E REPRESENTAÇões SociaIS
}

\author{
Ana Paula Meneses Alves* \\ Márcia Niituma Ogata** \\ Wilson José Alves Pedro***
}

\section{Resumo}

Partindo da visão interdisciplinar do campo denominado Ciência, Tecnologia e Sociedade (CTS), objetivamos apreender as abordagens sobre as teorias de Identidade e Representações Sociais na área de Ciência da Informação, por meio da análise de periódicos dessa área. Avaliamos revistas classificadas como Qualis A Nacional no conceito da Capes seguindo um critério pré-determinado. Localizados os artigos, foi realizada a análise; verificada qual abordagem teórica tratada; e consideradas as especificidades, pluralidade, dinâmica e complexidade de cada enfoque. Foram recuperados oito artigos. Com relação à Identidade é possível verificar que nenhum dos artigos identificados se baseou no mesmo referencial teórico com que trabalhamos (Ciampa). Para a teoria de Representações Sociais, todos os artigos selecionados estão em sintonia com a nossa abordagem teórica(Moscovici). Do ponto de vista metodológico, vários procedimentos foram utilizados, muitos deles retomando a questão da interdisciplinaridade e as vantagens advindas da interação entre áreas. Otipo de pesquisa mais utilizado foi o de natureza qualitativa. Para a análise de dados, destacamos a técnica do Discurso de Sujeito Coletivo de Lefêvre e Lefêvre. Os instrumentos de coleta de dados mais empregados foram os questionários e as entrevistas. Nesse trilhar, foi possível compreender e reafirmar que as áreas têm muito a crescer e a acrescentar entre si.

\footnotetext{
*Mestranda em Ciência, Tecnologia e Sociedade. UFSCar - Universidade Federal de São Carlos. Centro de Educação e Ciências Humanas - Programa de Pós-Graduação em Ciência, Tecnologia e Sociedade. São Carlos (SP). Bibliotecária. Unesp - Universidade Estadual Paulista. Faculdade de Ciências - Biblioteca da Faculdade de Ciências e Letras. E-mail: anameneses@fclar.unesp.br.

**Doutora em Enfermagem (USP). Professora-associada da UFSCar - CCBS - DEnf - Curso de Enfermagem - Programa de Pós-Graduação em Enfermagem e ao CECH - Programa de Pós-Graduação em Ciência, Tecnologia e Sociedade. São Carlos (SP)E-mail: ogata@ufscar.br.

***Doutor em Psicologia Social (PUC-SP). Professor-adjunto da UFSCar - CCBS - Denf - Curso de Gerontologia. Docente do PPG Ciência Tecnologia e Sociedade - UFSCar e Docente-colaborador do PPG Mestrado Profissional em Engenharia da Produção Uniara. São Carlos (SP). E-mail: wilsonpedro@ ufscar.br.
} 
PalaVras-chave: Identidade; Representações sociais; Ciência da Informação; Ciência, Tecnologia Sociedade.

\section{INTRODUÇÃo}

A maturidade e a história da Ciência nos permite afirmar que a mesma se desenvolveu como resultado das buscas para a compreensão da realidade. Essa tarefa nunca foi fácil, pois trata de dimensões complexas e dinâmicas. Fazer análises críticas sobre o reconhecer e conhecer nossa realidade, opinião ou mesmo uma área sempre foi um desafio para as diversas áreas do conhecimento e para a própria sociedade, que por muito tempo se apoiou na ideia de que Ciênciae Tecnologia (C\&T) seria a solução de todos os problemas. Alvarez (2001,p.75) nos lembra que:

A ciência moderna se constituiu historicamente como um empreendimento especializado, voltado para uma compreensão aprofundada de aspectos circunscritos da realidade. $\mathrm{O}$ grande sucesso prático desse novo empreendimento fez com que o conhecimento científico deslocasse com sucesso as antigas formas de compreensão da realidade - como por exemplo, o mito ou a religião - ao assumir o papel de principal discurso de compreensão e legitimação da modernidade.

Sabe-se da importância dos discursos científicos, mas também deve ficar clara a necessidade de olhares analíticos e críticos para compreender todas as transformações resultantes do desenvolvimento científico-tecnológico dos últimos tempos. Umespectro dessa visão mais crítica é o que apreende que a união e a interação entre diversos campos científicos podem impulsionar uma melhor compreensão da realidade. Esse é o espectro da interdisciplinaridade, que "[...] pressupõe disciplinas que trabalham um projeto comum, que tendem a se ajustar em sua essência, em seus conceitos, em seus métodos em prol deste projeto" (SOARES, 2001, p.83). É, também, o olhar do campo de estudos denominado Ciência, Tecnologia e Sociedade (CTS), sob o qual se vincula o presente estudo.

O campo CTS surgiu do Movimento Ciência, Tecnologia e Sociedade, iniciado no Hemisfério Norte nas décadas de 60 e 70, que contestava fortemente a concepção clássica da Ciência, e buscava uma percepção mais crítica para o papel desempenhado pela $C \& T$ e a defesa de que C\&T não estão desvinculadas das questões sociais. $\mathrm{O}$ movimento busca contribuir para a solução dos desafios econômicos, sociais e ambientais que impactam o mundo atual. Desde 2007 existe um Programa de Pós-Graduação nesse campo como intuito de criar, analisar e difundir novos conhecimentos e práticas 
sobre as relações que estabelecem entre Ciência, Tecnologia e Sociedade, visando à integração das novas tecnologias com as inovações sociais em direção a uma sociedade sustentável.

O presente estudo é fruto de interesse comum e de articulação entre áreas do saber. O grupo de pesquisadores responsável por este trabalho, advindos de áreas complementares -Psicologia Social \& Saúde Coletiva, que se encontram comCiência da Informação -, propõe um exercício dialógico no campo CTS, para apreender as produções, interfaces e possibilidades do emprego de aportes teórico-metodológicos das Teorias da Identidade e Representações Sociais na área de Ciência da Informação, a partir da análise de periódicos desta área. O artigo relata elementos dos aportes teóricometodológicos, etapas do método e analisa resultados.

\section{APORTES TEÓRICOS: IDENTIDADE, REPRESENTAÇÕES SOCIAIS E CIÊNCIA DA INFORMAÇÃo}

Compreender a realidade, as áreas científicas, a complexidade tecnológica e suas consequências, as ideias de um determinado grupo ou de umindivíduo, demanda estudos de diversas áreas do conhecimento, dentre elas as concepções advindas da Psicologia Social, meio de origem dos estudos sobre Identidade e Representações Sociais. A Psicologia Social surgiu como uma forma de ligação entre a Psicologia e a Sociologia e tem como objeto de estudo o comportamento dos indivíduos quando em interação. Esta área do conhecimento trabalha com conceitos e métodos fundamentais para a pesquisa de intervenção psicossocial, para observar e compreender as relações e interações indivíduo-sociedade, bem como a natureza e as causas do comportamento e do pensamento do indivíduo em situações sociais.

A Psicologia Social sempre enfrentou vários desafios; dizer apenas que busca entender as relações estabelecidas entre o indivíduo e a sociedade pode não abranger toda sua complexidade:

O ser humano traz consigo uma dimensão que não pode ser descartada, que é a sua condição social e histórica, sob o risco de termos uma visão distorcida (ideológica) de seu comportamento. Um outro ponto de desafio para a Psicologia Social se colocava diante dos conhecimentos desenvolvidos - sabíamos das determinações sociais e culturais de seu comportamento, [...] a criatividade, o poder de transformação da sociedade por ele construída (LANE, 1991b, p.12).

Pedro e Ogata (2008) também trabalham essa questão e afirmam que o saber da Psicologia Social ultrapassa os limites da junção de palavras, deve e é realizado emuma perspectiva interdisciplinar: 
A individuação das ciências humanas e sociais ao longo do século XX reproduziu a antinomia indivíduo e sociedade, dificultando a construção de paradigmas capazes de compreender o humano nas suas especificidades, bem como na sua totalidade, simultaneamente. Este legado merece ser resgatado no interior do pensamento científico contemporâneo (PEDRO, 2006) e certamente ao refletir sobre ciência, tecnologia e sociedade, este debate está presente (PEDRO; OGATA, 2008, p.69).

Devido a essa perspectiva interdisciplinar, na busca pelas melhores maneiras de observar os fenômenos psicossociais destacam-se as teorias de Identidade e Representações Sociais.

A Teoria da Identidade nos faz refletir sobre a síntese de nós mesmos. As questões "Quem sou eu?" e "Quemé você?" são premissas básicas e norteadoras para se delinear as considerações e representações a respeito de si próprio e o seu "estar no mundo". Pedro (2005, p.110-111) aponta que:

Para a Psicologia Social, a Identidade representa e engendra sentimentos que o indivíduo desenvolve a respeito de si e que é construída socialmente, a partir de seus dados pessoais, sua história de vida e seus atributos (conferidos por si mesmo e pelas outras pessoas), acompanhando o movimento deste no mundo social. Uma questão central no âmbito da Psicologia Social é como compreender a interação indivíduo-sociedade. Pensar a identidade implica resgatar as atividades e o processo de consciência do indivíduo. Implica nas mudanças processadas em sua história pessoal e em suas relações. A identidade é um processar contínuo da definição de si mesmo, das representações deste e de seu "estar" no mundo. É, portanto, movimento e dialética.

Identidade é o que nos caracteriza, o que nos define a partir de nossas vivências, de nossas relações como outro, de nossas atitudes, do desempenho dos nossos papéis na sociedade. É diversidade, é movimento, é transformação. "Identidade é movimento, é desenvolvimento do concreto. Identidade é metamorfose. É sermos o Ume um Outro, para que cheguemos a ser Um, numa infindável transformação" (CIAMPA, 1991, p.74).

Para compreender o que é identidade é preciso contextualizá-la, lembrar que está constantemente ligada com a história do indivíduo, as suas construções sociais, políticas e materiais, as tensões entre o individual e o coletivo. Pedro (2006, p.71) defende "[...] o projeto de analisar/compreender a identidade-metamorfose humana, inspirado 
na busca de conceitualizações que contemplem a dialética entre o psicológico, o social e o simbólico".

Outra abordagem relevante para os estudos da Psicologia Social é a Teoria das Representações Sociais, desenvolvida pelo psicólogo social romeno, naturalizado francês, Serge Moscovici. Seus trabalhos têm influenciado diversos estudos na área de Psicologia, História e Ciências Sociais. Moscovici acredita não haver um conceito definido para a teoria, mas concepções como as seguintes, apresentadas pelo teórico e por uma de suas principais seguidoras, Denise Jodelet:

É um conjunto de conceitos, proposições e explicações originadas na vida cotidiana no curso das comunicações interpessoais. Elas são o equivalente, em nossa sociedade, aos mitos e sistemas de crença das sociedades tradicionais; podem ser vistas como a versão contemporânea do senso comum (MOSCOVICI, 1981, p.181 apud PEDRO; OGATA, 2008, p.70).

O termo Representações Sociais engloba tanto um conjunto de fenômenos quanto o conceito e a teoria criados para explicá-los. Para fazer frente à perspectiva individualista presente na Psicologia Social na época - década de 70 -, Moscovici recorre ao pensamento sociológico de Durkheim e seu conceito de Representações Coletivas, que buscava compreender, entre outros, fenômenos como a religião, a ciência, os mitos, as categorias de espaço e tempo, em termos de conhecimentos constitutivos à sociedade (SÁ, 1995). "As representações que são a trama da vida social originam-se das relações que se estabelecem entre os indivíduos assim combinados ou entre grupos secundários que se intercalamentre o indivíduo e a sociedade total" (DURKHEIN, 1975, p.38 apud MORIGI; SILVA, 2005, p.129). Sá (1995, p.21) relembra que para Durkheim a "sociedade é uma realidade sui generis" e que fatos reais, coisa, reais por elas mesmas, sãos as representações coletivas que a exprimem.

O objetivo principal das Representações Sociais é conhecer e compreender o modo como determinado grupo elabora e compartilha socialmente ideias e saberes que refletem sua identidade. Para isso, as representações devem ser construídas sobre um conjunto de códigos culturais que definem em um determinado contexto (momento histórico) as regras de um grupo ou comunidade (PEDRO; OGATA, 2008).

Para dar seguimento ao nosso estudo é necessário também rever alguns conceitos que caracterizam a área de Ciência da Informação. Tendo a informação como objeto de estudo, e preocupando-se com as relações sociais envolvidas em seus processos de tratamento e acesso (ALMEIDA, 2006), bem como seu planejamento, organização e uso, esta área também se caracteriza como interdisciplinar e de grande importância para 
compreender e auxiliar a sociedade moderna. Na atualidade, a informação é considerada o principal insumo para o desenvolvimento da maioria das atividades humanas. Para iniciarmos essas considerações, recorremos a um dos principais teóricos da área, YvesFrançois Le Coadic (1996, p.26), que afirma que a Ciência da Informação:

Tem por objeto o estudo das propriedades gerais da informação (natureza, gênese, efeitos), ou seja, mais precisamente: a análise dos processos de construção, comunicação e uso da informação; e a concepção dos produtos e sistemas que permitem sua construção, comunicação, armazenamento e uso.

Saracevic (1996) destaca que há três características gerais que implicama existência e a evolução da Ciência da Informação: a natureza interdisciplinar está intimamente ligada à Tecnologia da Informação (e impõe transformações importantes no campo) e, juntamente com outras disciplinas, tem uma participação ativa e deliberada na evolução da chamada Sociedade da Informação.

A Ciência da Informação é um campo recente e em formação, e ainda perpassa por diversas discussões a respeito do seu método e objeto. Alves et al. (2007) apontam que, como seu objeto está sujeito a abordagens interdisciplinares e, aliando este fato ao pluralismo metodológico, é possível conferir à Ciência da Informação o status de ciência pós-moderna, mas ainda em busca de sua própria estruturação. Como uma ciência interdisciplinar, procura integrar diversas áreas do saber, como as humanidades, as ciências da saúde, da terra e as exatas.

\section{O PASSO-A-PASSO}

Do ponto de vista da abordagem do problema, trata-se de uma pesquisa qualitativa, e do ponto de vista dos objetivos, de uma pesquisa exploratória e descritiva. Quanto aos procedimentos técnicos, realizamos uma pesquisa bibliográfica, que buscou rever pontos e conceitos das áreas investigadas, a descrição e categorização dos dados e, posteriormente, as considerações sobre estes, observando se os pontos iniciais foram realmente localizados.

Para efetivação dessa proposta se definiram parâmetros, permitindo delimitar a recuperação de artigos científicos da área de Ciência da Informação que apreendessem as abordagens de Identidade e Representações Sociais. Os parâmetros adotados foram os seguintes: 1) Revistas Qualis A Nacional; 2) Área de avaliação: Ciências Sociais Aplicadas; 3) Ciência da Informação; 4) Brasil; 5)Voltadas para aárea de Biblioteconomia; 6) Disponível on-line; 7) Permite o recurso da pesquisa em toda a coleção disponível online; 8) Período: 2005 a 2008; 9) Apenas artigos e/ou relatos de pesquisa serão 
selecionados; 10) Termos pesquisados: identidade e representações; 11) Tema principal: identidade e representações sociais.

Optou-se por trabalhar com revistas QualisANacional pela representatividadee impacto das mesmas na área escolhida. O Qualis é uma classificação, resultante do processo de avaliação dos veículos de divulgação dos programas de pós-graduação pela Coordenação de Aperfeiçoamento de Pessoal de Nível Superior (Capes). Segundo o órgão:

A classificação é feita ou coordenada pelo representante de cada área e passa por processo anual de atualização. Os veículos de divulgação citados pelos programas de pós-graduação são enquadrados em categorias indicativas da qualidade - $\mathrm{A}, \mathrm{B}$ ou $\mathrm{C}-\mathrm{e}$ do âmbito de circulação dos mesmos - local, nacional ou internacional. As combinações dessas categorias compõem nove alternativas indicativas da importância do veículo utilizado e, por inferência, do próprio trabalho divulgado (CAPES, 2008).

Atualmente a área de Ciência da Informação se enquadra, de acordo coma tabela de áreas do conhecimento da Capes, como uma Ciência Social Aplicada.

Seguindo a delimitação, o próximo passo foi estabelecer um limite "espacial". Como espaço geográfico de publicação, apenas as revistas publicadas no Brasil foram selecionadas, pois a tabela abrange também publicações estrangeiras indicadas pelos programas de pós-graduação. Após este passo, o número foi reduzido para sete publicações.

Para focar ainda mais a pesquisa, o próximo parâmetro foi selecionar os periódicos voltados à Biblioteconomia. Aárea foi selecionada por ser a formação de origem de uma das pesquisadoras e a inicialmente observada pela pesquisa. Saracevic (1996) coloca que o campo comumentre a Biblioteconomia e a Ciência da Informaçãoé bastante forte e se baseia no compartilhamento de seu papel social e sua preocupação comum com os problemas relacionados ao uso efetivo dos registros gráficos. Mas o autor lembra que também existem diferenças entre elas:

[...] (1) seleção dos problemas propostos e a forma de sua definição; (2) questões teóricas apresentadas e os modelos explicativos introduzidos; (3) natureza e grau de experimentação e desenvolvimento empírico, assim como o conhecimento prático/competências derivadas; (4) instrumentos e enfoques usados; e (5) a natureza e a força das relações interdisciplinares estabelecidas e sua dependência para o avanço e evolução dos enfoques interdisciplinares (SARACEVIC, 1996, 49). 
Com esta última seleção, o painel de publicações foi reduzido a seis periódicos. Buscando facilitar a coleta de dados, classificaram-se apenas periódicos disponíveis online e que permitiam o recurso de pesquisa em toda a coleção disponível na internet. Essa opção se deve às vantagens do formato eletrônico, como a facilidade de acesso, rapidez e destreza da pesquisa devido aos recursos informacionais disponíveis. Observou-se também umperíodo comum para a análise (2005-2008), visando a uma uniformidade na verificação. Optou-se por selecionar apenas artigos originais e relatos de pesquisa, descartando os de revisão (reviews), resenhas, apresentações, editoriais, resumos, teses e dissertações, entre outros formatos de apresentação de texto em periódicos. Como resultado, cinco revistas foram escolhidas e avaliadas, como exposto no Quadro 1:

\begin{tabular}{|c|}
\hline Título do periódico $^{\mathbf{1}}$ \\
\hline Ciência da Informação \\
\hline Encontros Bibli (UFSC) \\
\hline Informação \& Sociedade. Estudos \\
\hline Perspectivas em Ciência da Informação \\
\hline Transinformação \\
\hline
\end{tabular}

Quadro 1. Revistas selecionadas para a análise.

Com as revistas selecionadas, começaram as primeiras análises e pesquisas em seus conteúdos. Os termos utilizados para a recuperação das informações foram: identidade e representações. Preferimos termos gerais para selecionar o maior número de artigos e, posteriormente, afunilar a seleção pelo tema (objetivo principal), no caso, identidade e representações sociais, segundo a revisão de literatura realizada nas primeiras seções deste artigo. Os resultados dessa etapa foram tabulados e serão apresentados e comentados na seção seguinte.

\section{Resultados}

A primeira pesquisa, pelas palavras-chave identidade e representações, localizou nos 5 periódicos avaliados 40 artigos que deveriam ser submetidos ao último parâmetro da análise: tema principal-identidade e representações sociais. O periódico Perspectivas em Ciência da Informação não teve nenhum texto selecionado após a aplicação dos critérios.

No total foramoito artigos recuperados. Para melhor compreensão, construíram-se

\footnotetext{
${ }^{1}$ Nos quadros os periódicos selecionados serão apresentados pelos seus respectivos títulos abreviados: Ciência da Informação = Cien. inf, Encontros Bibli = Enc. Bibli., Informação \& Sociedade: Estudos = Inf. soc, Perspectivas em Ciência da Informação = Perspect. cienc. Inf., Transinformação $=$ Transinf.
} 
quadros dos resultados para Identidade e Representações Sociais separadamente, conforme exposto nos Quadros 2 e 3:

\begin{tabular}{|c|c|c|c|c|c|}
\hline Artigo & Revista & Edição & Autor & Título & $\begin{array}{l}\text { Assunto Principal } \\
\text { (Palavra-chave) }\end{array}$ \\
\hline 1 & Cien. Inf & v. 35, n. 2,2006 & Isa M. Freire & $\begin{array}{l}\text { Acesso à informação e identidade } \\
\text { cultural: entre o global e o local }\end{array}$ & Identidade cultural \\
\hline 2 & Cien. Inf & v. $35, \mathrm{n} .3,2005$ & Isa M. Freire & $\begin{array}{l}\text { Janelas da cultura local: abrindo } \\
\text { oportunidades para inclusão digital } \\
\text { de comunidades }\end{array}$ & Identidade cultural \\
\hline 3 & Inf. Soc. & v. $16, \mathrm{n} .1,2006$ & $\begin{array}{l}\text { Femanda I. C. da } \\
\text { Silva; Edivanio D. de } \\
\text { Souza }\end{array}$ & $\begin{array}{l}\text { Informação e formação da } \\
\text { identidade cultural: o acesso à } \\
\text { informação na literatura de cordel }\end{array}$ & Identidade Cultural \\
\hline 4 & Inf. Soc. & v.16,n.1, 2006 & $\begin{array}{l}\text { Francisco das C. de } \\
\text { Souza }\end{array}$ & $\begin{array}{l}\text { A formação acadêmica de } \\
\text { bibliotecários e cientistas da } \\
\text { informação e sua visibilidade, } \\
\text { identidade e reconhecimento social } \\
\text { no Brasil }\end{array}$ & Identidade Profissional \\
\hline
\end{tabular}

Quadro 2. Resultado final da seleção de artigos sob o tema "Identidade".

\begin{tabular}{|c|c|c|c|c|c|}
\hline Artigo & Revista & Edição & Autor & Título & Assunto Principal \\
\hline 5 & $\begin{array}{l}\text { Enc. } \\
\text { Bibli. }\end{array}$ & v.12,n.24, 2007 & Manoela M. de Medeiros & $\begin{array}{l}\text { Informaçãoe } \\
\text { representações } \\
\text { sociais: um estudo } \\
\text { com familiares de } \\
\text { portadores de } \\
\text { sofrimento mental } \\
\end{array}$ & Representações sociais \\
\hline 6 & $\begin{array}{l}\text { Enc. } \\
\text { Bibli. }\end{array}$ & v $13, \mathrm{n} .25,2008$ & Renée R V Nina & $\begin{array}{l}\text { O bibliotecário como } \\
\text { profis sional da } \\
\text { informação e as } \\
\text { representações de } \\
\text { suas competências } \\
\text { profissionais e } \\
\text { pessoais para atuar em } \\
\text { bibliotecas } \\
\end{array}$ & $\begin{array}{l}\text { Representações sociais } \\
\text { (representações de competências) }\end{array}$ \\
\hline 7 & Inf. Soc. & v.15, n. 1,2005 & $\begin{array}{l}\text { Valdir J. Morigi; Magali L. } \\
\text { da Silva }\end{array}$ & \begin{tabular}{|l|} 
Paradigma \\
tecnológico e \\
representações sociais \\
dos bibliotecários \\
sobre seu perfil e suas \\
práticas no contexto \\
da Sociedade da \\
Informação
\end{tabular} & Representaçôes Sociais \\
\hline 8 & Transinf. & v. $18, \mathrm{n} .3,2006$ & Carlos C. de Almeida & $\begin{array}{l}\text { A Ciência da } \\
\text { Informação e a } \\
\text { sociedade brasileira: } \\
\text { algumas } \\
\text { representações de } \\
\text { pesquisadores da área }\end{array}$ & Representações Sociais \\
\hline
\end{tabular}

Quadro 3. Resultado final da seleção de artigos sob o tema "Representações sociais".

Com relação à Identidade é possível verificar que, dentre os artigos identificados, há uma ausência de explicitação do referencial teórico em análise. O que se observa é que, para a área os estudos relacionados à Identidade, há prevalência de expressões "identidade cultural" e "identidade profissional". Para a teoria de Representações Sociais, todos os artigos selecionados estão em sintonia com a nossa abordagem teórica. Os Quadros 4 e 5 confirmam esta análise ao delinear a abordagem teórica e os objetivos principais das pesquisas. 


\begin{tabular}{|r|l|l|l|}
\hline Artigo & $\begin{array}{l}\text { Assunto Principal } \\
\text { (Palavra-chave) }\end{array}$ & Abordagem teórica & Objetivo da pesquisa \\
\hline 1 & Identidade cultural & $\begin{array}{l}\text { HALL, S. A identidade cultural na pós- } \\
\text { modemidade. 2. ed. Rio de Janeiro: } \\
\text { DP\&A, 1998. }\end{array}$ & $\begin{array}{l}\text { Apresentar o quadro teórico e } \\
\text { metodológico da pesquisa Janelas } \\
\text { da Cultura Local, }\end{array}$ \\
\hline 2 & Identidade cultural & $\begin{array}{l}\text { HALL, S. A identidade cultural na pós- } \\
\text { modemidade. 2. ed. Rio de Janeiro: } \\
\text { DP\&A, 1998. }\end{array}$ & $\begin{array}{l}\text { Relatar os resultados parciais da da } \\
\text { pesquisa Janelas da Cultura Local: } \\
\text { Quissamã, RJ. }\end{array}$ \\
\hline 3 & Identidade Cultural & $\begin{array}{l}\text { CASTELLS, M. O poder da identidade. } \\
\text { São Paulo: Paz e Terra, 1999. }\end{array}$ & $\begin{array}{l}\text { Analisar os conteńdos } \\
\text { disseminados na literatura de cordel } \\
\text { como contribuição no processo de } \\
\text { construção e manutenção da } \\
\text { identidade cultural. }\end{array}$ \\
\hline 4 & $\begin{array}{l}\text { Apresentar uma análise da } \\
\text { formação acadêmica, da identidade } \\
\text { eda visibilidade profissional do } \\
\text { bibliotecário e do cientista da } \\
\text { informação, tomando como base a } \\
\text { literatura brasileira em } \\
\text { Biblioteconomia e Ciência da } \\
\text { Informação. }\end{array}$ \\
\hline
\end{tabular}

Quadro 4. Delineamento da abordagem teórica e objetivo principal da pesquisa (Identidade).

\begin{tabular}{|c|c|c|c|}
\hline Artigo & Assunto Principal & Abordagem teórica & Objetivo da pesquisa \\
\hline 5 & Representações sociais & $\begin{array}{l}\text { MOSCOVICI, S.. Representações sociais: } \\
\text { investigações em psicologia social. } \\
\text { Petrópolis: Vozes, 2003. } \\
\text { SÁ,C. P de. Núcleo central das } \\
\text { representações sociais. Petrópolis, RJ: } \\
\text { Vozes, 1996. } \\
\text { SPINK, M. J. O conceito de representação } \\
\text { social na abordagem psicossocial.Cademos } \\
\text { de Saúde Pública, Rio de Janeiro, v. } 9 \text { n.3, } \\
\text { p. 300-308, jul./set. } 1993 \text {. }\end{array}$ & $\begin{array}{l}\text { Verificar a viabilidade de aplicação da } \\
\text { teoria das representações sociais em } \\
\text { estudos de usuários em Ciência da } \\
\text { Informação. }\end{array}$ \\
\hline 6 & $\begin{array}{l}\text { Representações sociais } \\
\text { (representações de } \\
\text { competências) }\end{array}$ & $\begin{array}{l}\text { DURKHEIM, E As regras do método } \\
\text { sociológico: texto integral. São Paulo: } \\
\text { Martin Claret, 2003. } \\
\text { MOSCOVICI, S. Representações sociais: } \\
\text { investigações em psicologia social. 2. ed. } \\
\text { Petrópolis: Vozes, 2004. }\end{array}$ & $\begin{array}{l}\text { Conhecer as representações de } \\
\text { competências socialmente construídas } \\
\text { pelo profissional da informação - } \\
\text { bibliotecário, inserido no cenário atual } \\
\text { da explosão informacional, } \\
\text { conseqüência das inovações } \\
\text { tecnológicas e da globalização da } \\
\text { informação. }\end{array}$ \\
\hline 7 & Representações Sociais & $\begin{array}{l}\text { DURKHEIM, E. Representações } \\
\text { individuais e representações coletivas. In: } \\
\text {. Filosofia e sociologia. 2.ed. Rio de } \\
\text { Janeiro : Forense Universitária, 1975.p.15- } \\
49 . \\
\text { MOSCOVICI, S. A representação social na } \\
\text { psicanálise. Rio de Janeiro: Jorge Zahar, } \\
1978 . \\
\text { MOSCOVICI, S. Representações sociais: } \\
\text { investigações em Psicologia Social. } \\
\text { Petrópolis: Vozes, 2003. }\end{array}$ & $\begin{array}{l}\text { Discute os impactos sociais, as } \\
\text { mudanças e o redimensionamento nas } \\
\text { rotinas do trabalho dos bibliotecários } \\
\text { provocadas pelo uso e a constante } \\
\text { mediação tecnológica }\end{array}$ \\
\hline & Representações Sociais & $\begin{array}{l}\text { MOSCOVICI, S. Representações sociais: } \\
\text { investigações em Psicologia Social. } \\
\text { Petrópolis: Vozes, 2003. }\end{array}$ & $\begin{array}{l}\text { Conhecer as representações do campo } \\
\text { da Ciência da Informação, expressas } \\
\text { por seus pesquisadores no Brasil. }\end{array}$ \\
\hline
\end{tabular}

Quadro 5. Delineamento da abordagem teórica e objetivo principal da pesquisa (Representações sociais). 
Ao rever mais detalhadamente a abordagem teórica para Identidade, em três artigos encontrados (FREIRE, 2006a, 2006b, SILVA; SOUZA, 2006) destacam-se referência de Stuart Hall e Manuel Castells. Hall (2003) aponta que a identidade é algo que se vai formando ao longo do tempo, que está sempre em formação por meio de processos inconscientes, argumentação que vai de encontro à afirmação de Ciampa (1991), ao indicar que identidade é movimento, transformação ou ainda "[...] umprocesso permanente de formação e transformação do sujeito humano, que se dá dentro de condições materiais e históricas dadas" (CIAMPA, 1993, p.174 apud PEDRO; OGATA, 2008, p.71). Hall destaca que a questão da identidade está sendo amplamente discutida no âmbito da teoria social. Recorda que velhas identidades estão em declínio, e este fato faz surgir novas identidades, fragmentando o indivíduo moderno. Comrelação a identidades culturais, Hall (2003, p.8) argumenta que são "[...] aqueles aspectos de nossas identidades que surgem de nosso 'pertencimento' a culturas étnicas, raciais, linguísticas, religiosas e, acima de tudo, nacionais". Nesse ponto podemos fazer um paralelo comPedro (2006), que, ao delimitar e contextualizar o quadro teórico sobre identidade, afirma que questões como a necessidade de contextualização, reivindicações existencialistas, a questão da identidade relacional, vinculada a condições sociais, materiais e simbólicas e, principalmente, que identidades não são unificadas, são reflexões que visam subsidiar os estudos sobre identidade nacional, um campo bem específico dentro dos estudos de identidade e que, conforme visto neste estudo, também tem fornecido subsídios para estudos na área de Ciência da Informação.

Silva e Souza (2006), em seu artigo selecionado, apostam nas considerações de Castells (1999, p.22 apud SILVA; SOUZA, 2006, p.216): "[...] entende-se por identidade cultural a fonte de significado e experiência de um povo". Silva e Souza completam ao dizer que "entender seus valores, perceber até que ponto são realmente importantes, significa a procura do homem por sua própria identidade, que, embora mesclada pelas diversas informações do ambiente cultural, precisa ser submetida à sua avaliação crítica". Sustentam que identidade é um elemento múltiplo, presente na memória cultural dos indivíduos, designando qual papel social este deve desempenharem determinada situação. O texto de Souza (2006) representa uma abordagem diferenciada dos artigos anteriores, pois se trata de revisão de literatura que se propõe a interpretar aspectos referentes à identidade e visibilidade do profissional bibliotecário. O autor apoia-se na questão "quem somos?" para discutir a identidade profissional do bibliotecário. Aqui novo paralelo com Pedro (2005, p.111), relembrando que "[...] identidade é um processar contínuo da definição de si mesmo, das representações deste e de seu 'estar' no mundo".

A abordagem de Souza (2006) já faz uma ponte para os estudos de Representações Sociais e demonstram o estreito limiar entre Identidade e Representações Sociais. Com relação a Representações, todos os artigos selecionados (NINA, 2008; MEDEIROS, 
2007; ALMEIDA, 2006; MORIGI; SILVA, 2005) têm como base teórica Moscovici e a maioria tambémrelembra as considerações de Durkheim. As abordagens atendem ao objetivo principal das Representações Sociais, atentando para o conhecimento e compreensão do modo como determinado grupo elabora e compartilha socialmente ideias e saberes.

Do ponto de vista metodológico, vários procedimentos foramutilizados, tanto para Identidade quanto para Representações Sociais, alguns nas duas teorias, retomando a questão da interdisciplinaridade e as vantagens advindas da interação entre áreas. Os Quadros 6 e 7 ilustram a questão:

\begin{tabular}{|c|c|c|c|c|}
\hline Artigo & Tipo de pesquisa & $\begin{array}{l}\text { Técnica de pesquisa e } \\
\text { análise de dados }\end{array}$ & $\begin{array}{l}\text { Instrumento de } \\
\text { coleta de dados }\end{array}$ & População/Itens avaliados \\
\hline 1 & $\begin{array}{l}\text { Pesquisa } \\
\text { participante/pesquisa } \\
\text { ação }\end{array}$ & $\begin{array}{l}1 \text { - Revisão de literatura / } 2 \text { - } \\
\text { Aplicação do projeto }\end{array}$ & $\begin{array}{l}\text { Feedback dado } \\
\text { pela comunidade } \\
\text { a partir de } \\
\text { reuniões/ } \\
\text { Diagnósticos }\end{array}$ & $\begin{array}{l}\text { Projeto em andamento com } \\
\text { moradores do município Quissamã, } \\
\text { RJ. }\end{array}$ \\
\hline 2 & $\begin{array}{l}\text { Pesquisa } \\
\text { participante/pesquisa } \\
\text { ação }\end{array}$ & $\begin{array}{l}\text { 1- Revisão de literatura / } 2 \text { - } \\
\text { Aplicação do projeto }\end{array}$ & $\begin{array}{l}\text { Feedback dado } \\
\text { pela comunidade } \\
\text { a partir de } \\
\text { reuniões / } \\
\text { Diagnósticos }\end{array}$ & $\begin{array}{l}\text { Projeto em andamento com } \\
\text { moradores do município Quissamã, } \\
\text { RJ. }\end{array}$ \\
\hline 3 & Qualito-descritiva & Revisão de literatura & & $\begin{array}{l}\text { Análise de } 3 \text { cordéíis: "Os Costumes e } \\
\text { Usos Antigos" - Antonio Batista } \\
\text { Guedes: "A Guerra de Canudos" - } \\
\text { João Melquiades Ferreira da Silva; } \\
\text { "A Chegada de Lampeão no Infemo" } \\
\text { - Rodolfo Coelho Cavalcante. }\end{array}$ \\
\hline & Qualitativa & $\begin{array}{l}\text { - Revisão de literalura / } 2- \\
\text { Discurso de Sujeito Coletivo } \\
\text { (LEFEVRE; LEFEVRE, } \\
\text { 2003) }\end{array}$ & $\begin{array}{l}\text { Discursos viva- } \\
\text { voz e registros } \\
\text { pré-existentes }\end{array}$ & \\
\hline
\end{tabular}

Quadro 6. Identificação dos dados da pesquisas (Identidade).

\begin{tabular}{|c|c|c|c|c|}
\hline Artigo & $\begin{array}{l}\text { Tipo de } \\
\text { pesquisa }\end{array}$ & $\begin{array}{l}\text { Técnica de pesquisa e análise } \\
\text { de dados }\end{array}$ & $\begin{array}{l}\text { Instrumento de } \\
\text { coleta de dados }\end{array}$ & População/Itens avaliados \\
\hline 5 & Qualitativa & $\begin{array}{l}1 \text { - Revisão de literatura / } 2 \text { - } \\
\text { Abordagem Hermenêutico- } \\
\text { Dialética (MINAYO, 1996) }\end{array}$ & Entrevista & $\begin{array}{l}10 \text { familiares de portadores de } \\
\text { sofrimento mental }\end{array}$ \\
\hline 6 & $\begin{array}{l}\text { Quanti- } \\
\text { qualitaliva }\end{array}$ & $\begin{array}{l}1 \text { - Revisão de literatura / } 2 \text { - } \\
\text { Teoria do envolvimento e do } \\
\text { distanciamento da natureza } \\
\text { humana de Elias (1998)/3- } \\
\text { Discurso de Sujeito Coletivo } \\
\text { (LEFEVRE, LEFEVRE, 2003) }\end{array}$ & $\begin{array}{l}\text { 1- Questionário de } \\
\text { caracterização do } \\
\text { bibliotecário/ 2- } \\
\text { Roteiro semi- } \\
\text { estruturado de } \\
\text { entrevista ao } \\
\text { bibliotecário }\end{array}$ & $\begin{array}{l}28 \text { bibliotecários do sistema de } \\
\text { bibliotecas da UFAM }\end{array}$ \\
\hline 7 & Qualitativa & $\begin{array}{l}1 \text { - Revisão de literatura / } 2 \text { - } \\
\text { Pesquisa de campo (entrevista) } \\
\text { /3- Codificação e análise dos } \\
\text { dados }\end{array}$ & $\begin{array}{l}\text { Entrevista semi- } \\
\text { estruturada }\end{array}$ & $\begin{array}{l}11 \text { bibliotecários de universidades } \\
\text { públicas e privadas e } 2 \\
\text { bibliotecários consultores }\end{array}$ \\
\hline 8 & Qualitativa & $\begin{array}{l}1 \text { - Revisão de literatura / } 2- \\
\text { Discurso de Sujeito Coletivo } \\
\text { (LEFEVRE: LEFEVRE } 2003 \text { ) }\end{array}$ & Questionário & $\begin{array}{l}30 \text { pesquisadores com bolsa } \\
\text { produtividade do } \mathrm{CNPQ}\end{array}$ \\
\hline
\end{tabular}

Quadro 7. Identificação dos dados da pesquisas (Representações sociais). 
O tipo de pesquisa mais utilizado foi a pesquisa de natureza qualitativa, o que salienta a preocupação coma subjetividade dos temas e sua melhor forma de descrição. Para a análise de dados, apontamos a técnica do Discurso de Sujeito Coletivo de Lefêvre e Lefèvre, e destacamos para esta a leitura de Almeida (2006, p.173):

Para analisar os dados, utilizou-se a técnica chamada Discurso do Sujeito Coletivo (DSC), que é "[...] uma proposta de organização de dados qualitativos de natureza verbal, obtidos de depoimentos, artigos de jornal, matérias de revistas semanais, cartas, papers, revistas especializadas, etc." (LEFÈVRE; LEFÈVRE, 2003, p.15). O DSC consiste em uma estratégia diferente de categorização, pois não separa os discursos individuais dos coletivos, mas une-os em uma fala coletivizada. Uma das bases do DSC é a semiótica peirciana, principalmente as contribuições de Peirce (2000) relativas à cadeia semiótica. $\mathrm{O}$ discurso é entendido na concepção peirciana como signo de um objeto que evolui mediante as várias releituras que recebe, afastando-se do objeto de representação cada vez que é realizada uma nova releitura.

Os instrumentos de coleta de dados mais utilizados foram os questionários e as entrevistas, que permitemuma maior interação entre o pesquisador, o sujeito e a pesquisa que está sendo realizada. Enfim, as técnicas utilizadas também refletem a questão interdisciplinar, e acrescentam à área da Ciência da Informação métodos que podem contribuir para diversos estudos.

Alguns pontos merecemser destacados. Observa-se a questão da distribuição geográfica dos temas. Os estudos sobre Identidade na Ciência da Informação foram majoritariamente oriundos de periódicos das Regiões Centro-Oeste e Nordeste (Ci. Inf. e Inf. e Soc.), enquanto os estudos relacionados a Representações Sociais são oriundos de periódicos das Regiões Sul, Sudeste e Nordeste (Enc. Bibl., Inf. e Soc. e Trans.). Com relação à avaliação de Identidade, os autores representam, de acordo com suas afiliações declaradas, o Distrito Federale Alagoas; na questão de Representações Sociais, os Estados foram Minas Gerais, Amazonas, Santa Catarina e Rio Grande do Sul.

Quanto às temáticas específicas da área de Ciência da Informação (Biblioteconomia), que utilizaram as teorias de Identidade e Representações Sociais para contribuir nas suas práticas, estavam presentes nos artigos selecionados para o estudo:

$\checkmark$ Identidade: identidade cultural e fontes de informação; identidade culturale inclusão digital, papel da internet e Sociedade da Informação; identidade profissional e o papel do profissional da informação; identidade profissional e formação acadêmica em 
Biblioteconomia e Ciência da Informação;

$\checkmark$ Representações Sociais: Estudos de usuários; Competências profissionais; Perfil profissional; Representação e estudos sobre a própria área.

\section{Considerações FINAIS}

Um olhar crítico-analítico é um dos principais objetivos do campo CTS. Observar e apreender novas técnicas, estudos e possibilidades interdisciplinares que contribuam para atingi-lo é um dos pontos-chave para o sucesso nesta empreitada. Neste breve estudo, partindo dos subsídios do campo CTS, área comum dos três pesquisadores, se buscou trilhar os caminhos da interdisciplinaridade para compreender melhor os aspectos de suas áreas de origem e suas possíveis intersecções.

Neste trilhar foi possível compreender e reafirmar que as áreas têm muito a crescer e acrescentar umas às outras. Como pesquisadores, devemos deixar claro que, pelo rol de periódicos que trabalhamos, e sua importância e impacto para a área de Ciência da Informação, que nossa expectativa era a de encontrar muito mais do que apenas oito trabalhos que abordassem o tema Identidade e Representações Sociais. Mas não estamos aqui para encarar este fato como um ponto negativo. Em contrapartida, estamos aqui para ver novas oportunidades de trabalho e crescimento para nossos tópicos de avaliação. Percebe-se aqui uma pequena semente, que pode florir ótimos estudos para as três áreas e para o campo CTS.

\section{REFERÊNCIAS}

ALMEIDA, C. C. A Ciência da Informação e a sociedade brasileira: algumas representações de pesquisadores da área. Transinformação, Campinas, v.18, n.3, p.169-180, set./dez. 2006. Disponível em: <http://revistas.puc-campinas.edu.br/ transinfo/viewarticle.php?id=179>. Acesso em: 25 out. 2008.

ALVAREZ, M. C. Muito além das disciplinas. In: CARRARA, K. (Org.). Educação, universidade e pesquisa. Marília: UNESP Marília Publicações; São Paulo: FAPESP, 2001. p.75-77.

ALVES, R. C. V. et al. Ciência da Informação e a Pós-Modernidade: considerações sobre o status científico. Revista Eletrônica Informação e Cognição, Marília, v.6, n.1, p.41-54, 2007. Disponível em: <http:// www.portalppgci.marilia.unesp.br/reic/viewissue.php?id=9\#Artigos>. Acesso em: 29 out. 2008. 
CIMPA, A. da C. Identidade. In: LANE, S. T. M.; CODO, W. Psicologia Social: o homem em movimento. 9. ed. São Paulo: Brasiliense, 1991. p.58-75.

COORDENAÇÃO DE APERFEIÇOAMENTO DE PESSOAL DE NÍVEL SUPERIOR [CAPES]. Classificação de periódicos, anais, revistas e jornais. [QUALIS]. 2008. Disponível em: <http://qualis.capes.gov.br/webqualis/ Index.faces;jsessionid=1D9150AAB351305AD5E0C65E680285AD.srv06>. Acesso em 15 out. 2008.

FREIRE, I. M. Janelas da cultura local: abrindo oportunidades para inclusão digital de comunidades. Ciência da Informação, Brasília, v. 35, n. 3, p. 227-235, set./ dez. 2006a. Disponível em: <http://revista.ibict.br/index.php/ciinf/article/viewArticle/ 706>. Acesso em: 25 out. 2008.

. Acesso à informação e identidade cultural: entre o global e o local. Ciência da Informação, Brasília, v. 35, n. 2, p. 58-67, maio/ago. 2006b. Disponível em: <http://www.scielo.br/pdf/ci/v35n2/a07v35n2.pdf>. Acesso em: 25 out. 2008.

HALL, S. A identidade cultural na pós-modernidade. Tradução de Tomaz Tadeu da Silva e Guacira Lopes Louro. 7. ed. Rio de Janeiro: DP\&A, 2003.

LANE, S. T. M. O que é Psicologia Social. 17. ed. São Paulo: Brasiliense, 1991a. (Coleção Primeiros Passos, 39).

. APsicologia Social e uma nova concepção do homem para a Psicologia. In: LANE, S. T. M.; CODO, W. Psicologia Social: o homem em movimento. 9. ed. São Paulo: Brasiliense, 1991b. p.10-19.

LE COADIC,Y. F. A ciência da informação. Brasília, DF, Briquet de Lemos. 1996.

MEDEIROS, M. M. de. Informação e representações sociais: um estudo com familiares de portadores de sofrimento mental. Encontros Bibli: Revista Eletrônica de Biblioteconomia e Ciência da Informação, n.24, p.72-91, 2º sem. 2007. Disponível em: < http://www.periodicos.ufsc.br/index.php/eb/article/view/423>. Acesso em: 25 out. 2008.

MORIGI, V. J.; SILVA, M. L. da. Paradigma tecnológico e representações sociais 
dos bibliotecários sobre seu perfil e suas práticas no contexto da Sociedade da Informação. Informação \& Sociedade, João Pessoa, v.15, n.1, p.123-145, jan./ jun. 2005. Disponível em: <http://www.ies.ufpb.br/ojs2/index.php/ies/article/view/ 55/1525>. Acesso em: 25 out. 2008.

NINA, R. R. V. O bibliotecário como profissional da informação e as representações de suas competências profissionais e pessoais para atuar em bibliotecas. Encontros Bibli: Revista Eletrônica de Biblioteconomia e Ciência da Informação, n.25, p.105-123, $1^{\circ}$ sem.2008. Disponível em: <http:// www.periodicos.ufsc.br/index.php/eb/article/view/1515/1253/706>. Acesso em: 25 out. 2008.

ORTEGA, C. D. Relações históricas entre Biblioteconomia, Documentação e Ciência da Informação. DataGramaZero: Revista de Ciência da Informação, [S.1.], v.5, n.5, out. 2004. Disponívelem: 〈http://www.dgz.org.br/out04/Art_03.htm〉. Acesso em: 02 dez. 2008.

PEDRO, W. J. A. Reflexões sobre a categoria identidade através de uma perspectiva interdisciplinar. Revista Uniara, Araraquara, v.19, p.67-74, 2006. Disponível em: $<$ http://www.uniara.com.br/revistauniara/pdf/19/ Rev19completa_08.pdf>.Acesso em: 22 out. 2008.

. O estudo da identidade no âmbito da psicologia social brasileira. Revista Uniara, Araraquara, v.16, p.109-116, 2005. Disponível em: <http:// www.uniara.com.br/revistauniara/pdf/16/rev16completa_10.pdf $>$. Acesso em: 22 out. 2008.

PEDRO, W. J. A.; OGATA, M. N. Aportes teóricos e metodológicos para a compreensão das dimensões intersubjetivas e sociais na ciência e tecnologia. In: HOFFMANN, W. A. M.; FURNIVAL, A. C. M. Olhar: Ciência, Tecnologia e Sociedade. São Carlos: Pedro \& João Editores: CECH-UFSCar, 2008. p.67-75.

SÁ, C. P. de. Representações Sociais: o conceito e o estado atual da teoria. In: SPINK, M. J. P. (Org.). O conhecimento no cotidiano: as representações sociais na perspectiva da psicologia social. São Paulo: Brasiliense, 1995. p.19-45.

SARACEVIC, T. Ciência da informação: origem, evolução e relações.

Perspectivas em Ciência da Informação, Belo Horizonte, v. 1, n. 1, p. 41-62, 
jan./jun. 1996. Disponívelem: < http://www.eci.ufmg.br/pcionline/index.php/pci/ article/viewFile/235/22>. Acesso em 22 nov. 2008.

SILVA, F. I.C. da; SOUZA, E. D. de. Informação e formação da identidade cultural: o acesso à informação na literatura de cordel. Informação \&

Sociedade: Estudos, João Pessoa, v.16, n.1, p.215-222, jan./jun. 2006.

Disponível em: <http://www.ies.ufpb.br/ojs2/index.php/ies/article/view/455/ 1506>. Acesso em: 25 out. 2008.

SOARES, A. B. A ciência e a instituição no terceiro milênio: abordando a interdisciplinaridade. . In: CARRARA, K. (Org.). Educação, universidade e pesquisa. Marília: UNESP Marilia Publicações; São Paulo: FAPESP, 2001. p.79-90.

SOUZA, F. C. de. A formação acadêmica de bibliotecários e cientistas da informação e sua visibilidade, identidade e reconhecimento social no Brasil. Informação \& Sociedade: Estudos, João Pessoa, v.16, n.1, p.23-34, jan./jun. 2006. Disponívelem: <http://www.ies.ufpb.br/ojs2/index.php/ies/article/view/439/ 1491>. Acesso em: 25 out. 2008.

\section{Title: A Brief Analysis of Information SCIENCE Periodicals about the Identity AND SOCIAL REPRESENTATION THEORIES}

\section{ABSTRACT}

Based on an interdisciplinary view of the field of Science, Technology and Society (STS), we aim to understand the approaches to the Identity and Social Representation Theory in the Information Science field, by analyzing periodicals in this area. We evaluated scientific journals classified as Qualis A National, according to the CAPES concept, following pre-determined criteria. Once the articles were located, an analysis was performed, not only checking the theoretical approaches, but also considering the specificities, pluralities, dynamics and complexities of each approach. Eight articles were recovered. In relation to Identity, it is possible to verify that none of the identified articles was based on the same theoretical references that we have used (Ciampa). In relation to the theory of Social Representation, all the selected articles are in accordance with our theoretical approach (Moscovici). From the methodological point of view, a series of procedures were used, many of them reconsidering the interdisciplinary matter and the resulting advantages from interactions between areas. Qualitative nature research was the most used in the articles. Concerning data analysis, we emphasize 
the Lefévre and Lefévre Collective Subjective Discourse technique. The most used assessment tools were questionnaires and interviews. In this study it was possible to understand and reaffirm that these areas have much to contribute and add each other.

KEYWorDs: Identity; Social representations; Information Science; Science, Technology and Society. 